\title{
ULTRASOUND GUIDED TIBIAL NERVE BLOCK IN MANAGEMENT OF PAINFUL DIABETIC NEUROPATHY
}

\author{
By \\ *Hosny Abo Zied Farg, **Ali Abd Allah Eissa and *Wafaa Gaber \\ Ahmed \\ *Department of Anesthesia and Intensive Care, Faculty of Medicine (Girls), Al- Azhar \\ University \\ **Department of Anesthesia and Intensive Care, Faculty of Medicine, Al- Azhar \\ University \\ Corresponding author: Hosny Abo Zied Farg,
}

Mobile: 01095510006, E-mail: dr.hosnyfarag92@ gmail.com

\begin{abstract}
Background: Diabetic neuropathy (DN) refers to signs and symptoms of neuropathy in patients with diabetes in whom other causes of neuropathy have been excluded. Distal symmetrical neuropathy is the most common form accounting for $75 \%$ of $\mathrm{DN}$.

Objective: To determine the pain relief efficacy of three successive ultrasound guided tibial nerve block at the ankle with bupivacaine and betamethasone, as a primary outcome in the management of chronic painful diabetic neuropathy of the foot resistant to medical management, compared to ultrasound guided placebo tibial nerve block. Serum glucose levels for assessment of diabetes control and patients satisfaction were measured as a secondary outcome.

Patients and Methods: After obtaining the Ethics Committee's approval of Anesthesia Department of AlZahra'a University Hospital, and the patients' written informed consent, 40 Patients (aged 18-60y) with chronic painful distal diabetic polyneuropathy were prospectively enrolled in this double blind and random study. The patients were classified randomly into two equal groups: Group (I): Control group: patients who received ultrasound guided tibial nerve injection by sterile cold normal saline (28 $\square$ C), and Group (II): Steroid group: Patients received ultrasound guided tibial nerve injection by betamethasone ( $7 \mathrm{mg} \mathrm{amp}$ ) which was diluted in $7 \mathrm{ml}$ saline, then $1 \mathrm{mg}$ was diluted in $0.25 \%$ bupivacaine. Each limb was injected in both groups by three successive injections each other week in alteration with other limb, then followed up monthly for 3 months.
\end{abstract}

Results: Three successive ultrasound guided tibial nerve block at ankle level with $1 \mathrm{mg}$ betamethasone in $0.25 \%$ bupivacaine decreased LANSS score and analgesic requirements with more patient satisfaction in distal painful diabetic neuropathy resistant to medical treatment.

Conclusion: The therapeutic benefits provided by ultrasound guided tibial nerve block with bupivacaine and betamethasone more effective than placepo block. Pain and other symptoms decrease abruptly after the first tibial nerve block and disappear after the third tibial nerve block.

Keywords: Diabetic neuropathy, painful diabetic peripheral neuropathy, Betamethasone. 


\section{HOSNY ABO ZIED FARG et al.,}

\section{INTRODUCTION}

Peripheral neuropathy is characterized by diffuse damage to the peripheral nerve fibers. The commonest cause of peripheral neuropathy is diabetes, and $30-90 \%$ of patients with diabetes have peripheral neuropathy (Callaghan et al., 2012). Diabetic sensorimotor polyneuropathy, the most common type of diabetic neuropathy, is associated with an impaired quality of life, significant morbidity and increased healthcare costs. Additionally, $16-34 \%$ of patients with diabetes report painful neuropathic symptoms and the prevalence are greater in type 2 diabetes (Abbott et al., 2011).

The symptoms of painful diabetic neuropathy can be debilitating and can cause sleep disturbances, anxiety and interfere with physical functioning. Painful diabetic neuropathy represents an ongoing therapeutic challenge for patients and caregivers and it is thought that as many $(39 \%)$ of cases of Painful diabetic neuropathy may be resistant to treatment. Guidelines have been developed by professional organizations to provide a rational approach to the treatment of Painful diabetic neuropathy (Spallone, 2012).

Management of patients with DN entails control of hyperglycemia and other cardiovascular risk factors for neuropathic pain: Analgesics, non-steroidal anti-inflammatory drugs, anti-depressants, and anti-convulsants are recommended. Resistant cases for medical treatment in DN may need minimal invasive intervention (Bai-Chuang and Makoto, 2018).

Local anesthetic in isolation is used for either injection for diagnostic purposes or for acute pain relief in postoperative or post-traumatic situations so for treatment of painful diabetic neuropathy can combine with steroids, e.g methyl prednisolone and betamethasone which are alternatives to triamcinolone. They have anti-inflammatory and painmodulating effects but might take some time for its action, during which analgesia is provided by local anesthetics (Daftary and Karnik, 2015).

Ultrasounds use has been rated as one of the safest practices for patients. Some of the prerequisites for the implementation of ultrasounds in regional anesthesia include excellent understanding and knowledge of human anatomy (Gonano et al., 2009).

The present work aimed to determine the pain relief efficacy of three successive ultrasound guided tibial nerve block at the ankle with bupivacaine and betamethasone as a primary outcome in the management of chronic painful diabetic neuropathy of the foot resistant to medical management.

\section{PATIENTS AND METHODS}

After obtaining the Ethics Committee's approval of Anesthesia Department of AlZahra'a University Hospital, and the patients' written informed consent, 40 Patient (aged 18-60y) with chronic painful distal diabetic polyneuropathy were prospectively enrolled in this double blind, randomized controled study.

\section{Inclusion criteria:}

Adult males or females demonstrating at least moderate pain for at least $50 \%$ of the day for a minimum of 3 months, diabetic patient with controlled glucose 
level, and with a stable analgesic regimen for 3 months (consisting of more than two analgesics, including tricyclic antidepressants, anticonvulsants), and patients capable of appropriate response to the Leeds Assessment of Neuropathic Symptoms and Signs pain score (LANSS) and visual analogue scale (VAS) (Bennett et al., 2005).

Patients with another type of pain as severe as that caused by diabetic neuropathy, pregnancy or breast-feeding, signs or symptoms of any central neurological disorder or diagnosis of angle-closure glaucoma, active peptic ulcer, or a history of coagulopathy, or Infection at the site of injection were excluded from the study.

Patients were randomly assigned by computer generated random number in to tow equal groups: Group (I): Control group: Patients received ultrasound guided tibial nerve injection by sterile cold normal saline $\left(28^{\circ} \mathrm{C}\right)$ and Group (II): Steroid group: Patients received ultrasound guided tibial nerve injection by betamethasone the block was done at ankle level.

Routine preoperative assessment was done to all patients including history, clinical examination, laboratory investigations (fasting blood glucose and $2 \mathrm{~h}$ post prandial glucose level). Patients were instructed to use to (VAS) and (LANSS), score for pain assessment before and after intervention.

In steroid group, the treatment drug was $1 \mathrm{mg}$ betamethasone diluted in $0.25 \%$ bupivacine then injected in different planes until donut sign appearance.
Numbness and paresthesia occured quickly with full block onset in 515minutes.

In control group, sterile cold saline $\left(28^{\circ} \mathrm{C}\right)$ was injected in same way as in steroid groups.

Each limb was injected in both groups for three successive injections each other week in alteration with other limb, then followed up monthly for 3 months.

Pre block (VAS) and (LANSS) scores, and analgesic requirements were assessecled and recorded every week for 6 weeks then every month for 3 months.

Blood glucose level was measured pre block and every week during block periods.

Patient satisfaction score, (1- Un satisfied, 2- Satisfied, 3- Very satisfied) was recorded at the end of this study.

The sample size was calculated using Open Epi program version 3 according to a research done by Eissa et al. (2007), and the margin of error was accepted up to $5 \%$, the power of the test to $90 \%$, and the ratio between the two groups to $1: 1$. The total sample size needed for this study was found to be 10 patients divided into two equal groups each group 5 patients.

\section{Statistical Analysis:}

Data were collected, revised, coded and entered to the Statistical Package for the Social Science (IBM SPSS) version 23. The quantitative data were presented as mean, standard deviations and ranges when parametric. Also, qualitative variables were presented as number and percentages.

The comparison between groups regarding qualitative data was done by 
using Chi-square test and/or Fisher exact test when the expected count in any cell found less than 5 .

The comparison between two groups regarding quantitative data and parametric distribution was done by using Independent $t$-test.
The confidence interval was set to $95 \%$ and the margin of error accepted was set to $5 \%$.

$\mathrm{P}$-value $<0.05$ was considered significant.

\section{RESULTS}

There was no statistically significant difference found between the two studied groups regarding demographic data, ASA, duration of diabetes and neuropathy (Table 1).

Table (1): Comparison between control group and steroid group regarding demographic data, ASA, duration of diabetes and neuropathy

\begin{tabular}{|c|c|c|c|c|}
\hline \multirow{2}{*}{\multicolumn{2}{|c|}{$\begin{array}{|ll|}\text { Parameters } & \text { Groups } \\
\end{array}$}} & Control group & $\begin{array}{l}\text { Steroid } \\
\text { group }\end{array}$ & \multirow[t]{2}{*}{ P-value } \\
\hline & & No. $=20$ & No. $=20$ & \\
\hline \multirow{2}{*}{ Age(years) } & Mean \pm SD & $49.65 \pm 7.33$ & $50.35 \pm 7.49$ & \multirow{2}{*}{$0.767 \bullet$} \\
\hline & Range & $37-60$ & $35-60$ & \\
\hline \multirow{2}{*}{ Sex } & Females & $10(50.0 \%)$ & $8(40.0 \%)$ & \multirow{2}{*}{$0.525^{*}$} \\
\hline & Males & $10(50.0 \%)$ & $12(60.0 \%)$ & \\
\hline \multirow{2}{*}{ ASA } & II & $13(65.0 \%)$ & $14(70.0 \%)$ & \multirow{2}{*}{$0.736^{*}$} \\
\hline & III & $7(35.0 \%)$ & $6(30.0 \%)$ & \\
\hline \multirow{2}{*}{ Duration of diabetes(years) } & Mean \pm SD & $11.90 \pm 4.20$ & $12.35 \pm 4.97$ & \multirow{2}{*}{$0.756 \#$} \\
\hline & Range & $6-20$ & $4-25$ & \\
\hline \multirow{2}{*}{ Duration of neuropathy(years) } & Mean \pm SD & $5.85 \pm 2.46$ & $4.55 \pm 1.99$ & \multirow{2}{*}{$0.123 \#$} \\
\hline & Range & $2-10$ & $1-8$ & \\
\hline
\end{tabular}

Independent t-test; *: Chi-square test; \#: Mann-Whitney test

There was no statistically significant difference found between the two studied groups regarding LANSS score pre block, while there was a statistically significant decrease in LANSS score in steroid group compared to control group at different times of injection and follow up period (Table 2). 
ULTRASOUND GUIDED TIBIAL NERVE BLOCK IN MANAGEMENT...

Table (2): Comparison between control group and steroid group regarding LANSS score at different times of injection and follow up visits

\begin{tabular}{|c|c|c|c|c|}
\hline \multicolumn{2}{|c|}{ Parameters } & Control group & Steroid group & \multirow{2}{*}{ P- value\# } \\
\hline & Groups & No. $=20$ & No. $=20$ & \\
\hline \multirow{2}{*}{ pre block } & $18.35 \pm 2.96$ & $19.05 \pm 2.54$ & $18.35 \pm 2.96$ & \multirow{2}{*}{0.412} \\
\hline & $13-22$ & $15-23$ & $13-22$ & \\
\hline \multirow{2}{*}{ 1st week } & $18.15 \pm 3.10$ & $0.00 \pm 0.00$ & $18.15 \pm 3.10$ & \multirow{2}{*}{0.001} \\
\hline & $13-22$ & $0-0$ & $13-22$ & \\
\hline \multirow{2}{*}{$2 \mathrm{nd} w$} & $17.20 \pm 3.02$ & $0.00 \pm 0.00$ & $17.20 \pm 3.02$ & \multirow{2}{*}{0.001} \\
\hline & $12-22$ & $0-0$ & $12-22$ & \\
\hline \multirow{2}{*}{$3 r d w$} & $16.90 \pm 2.92$ & $0.00 \pm 0.00$ & $16.90 \pm 2.92$ & \multirow{2}{*}{0.001} \\
\hline & $12-21$ & $0-0$ & $12-21$ & \\
\hline \multirow{2}{*}{4 th w } & $16.65 \pm 3.27$ & $0.00 \pm 0.00$ & $16.65 \pm 3.27$ & \multirow{2}{*}{0.001} \\
\hline & $11-22$ & $0-0$ & $11-22$ & \\
\hline \multirow{2}{*}{5 th $w$} & $16.55 \pm 2.95$ & $0.00 \pm 0.00$ & $16.55 \pm 2.95$ & \multirow{2}{*}{0.001} \\
\hline & $12-22$ & $0-0$ & $12-22$ & \\
\hline \multirow{2}{*}{ 6th w } & $16.40 \pm 3.07$ & $0.00 \pm 0.00$ & $16.40 \pm 3.07$ & \multirow{2}{*}{0.001} \\
\hline & $12-21$ & $0-0$ & $12-21$ & \\
\hline \multirow{2}{*}{ 1st month } & $17.70 \pm 2.87$ & $0.10 \pm 0.45$ & $17.70 \pm 2.87$ & \multirow{2}{*}{0.001} \\
\hline & $13-22$ & $0-2$ & $13-22$ & \\
\hline \multirow{2}{*}{ 2nd month } & $18.35 \pm 2.96$ & $0.25 \pm 0.79$ & $18.35 \pm 2.96$ & \multirow{2}{*}{0.001} \\
\hline & $13-22$ & $0-3$ & $13-22$ & \\
\hline \multirow{2}{*}{ 3rd month } & $19.25 \pm 2.75$ & $0.25 \pm 0.79$ & $19.25 \pm 2.75$ & \multirow{2}{*}{0.001} \\
\hline & $14-23$ & $0-3$ & $14-23$ & \\
\hline
\end{tabular}

\#: Mann-Whitney test

There was no statistically significant difference found between the two studied groups regarding FBG at different times of injection (Table 3).

Table (3): Comparison between control group and steroid group regarding fasting blood glucose (FBG) at different times of injection

\begin{tabular}{|c|c|c|c|c|}
\hline \multirow{2}{*}{\multicolumn{2}{|c|}{ Parameters $\quad$ Groups }} & \multirow{2}{*}{$\begin{array}{c}\text { Control group } \\
\text { No. }=20 \\
\end{array}$} & \multirow{2}{*}{$\begin{array}{c}\text { Steroid group } \\
\text { No.=20 }\end{array}$} & \multirow{2}{*}{ P-value } \\
\hline & & & & \\
\hline \multirow{2}{*}{ 1st w BG } & Mean \pm SD & $106.20 \pm 9.63$ & $109.50 \pm 7.83$ & \multirow{2}{*}{0.242} \\
\hline & Range & $92-122$ & $95-121$ & \\
\hline \multirow{2}{*}{$2 \mathrm{nd} w$} & Mean \pm SD & $105.60 \pm 6.36$ & $109.40 \pm 7.14$ & \multirow{2}{*}{0.084} \\
\hline & Range & $93-118$ & $95-120$ & \\
\hline \multirow{2}{*}{$3 \mathrm{rd} \mathrm{w}$} & Mean \pm SD & $106.30 \pm 9.27$ & $109.40 \pm 7.29$ & \multirow{2}{*}{0.247} \\
\hline & \begin{tabular}{|l} 
Range \\
\end{tabular} & $89-121$ & $94-120$ & \\
\hline \multirow{2}{*}{ 4th $w$} & Mean \pm SD & $108.95 \pm 8.30$ & $112.00 \pm 7.68$ & \multirow{2}{*}{0.235} \\
\hline & Range & $95-124$ & $98-125$ & \\
\hline \multirow{2}{*}{5 th $w$} & Mean \pm SD & $108.45 \pm 8.43$ & $110.65 \pm 9.06$ & \multirow{2}{*}{0.431} \\
\hline & Range & $93-125$ & $90-122$ & \\
\hline \multirow{2}{*}{ 6th w } & Mean \pm SD & $109.25 \pm 8.42$ & $113.65 \pm 6.05$ & \multirow{2}{*}{0.065} \\
\hline & Range & $93-122$ & $99-125$ & \\
\hline
\end{tabular}

Independent t-test Fasting blood glucose (FBG).

There was no statistically significant difference found between the two studied groups regarding PPG at different times of injection (Table 4). 
Table (4): Comparison between control group and steroid group regarding post prandial gluconse (PPG) at different times of injection

\begin{tabular}{|c|c|c|c|c|}
\hline \multirow{2}{*}{\multicolumn{2}{|c|}{$\begin{array}{ll}\text { Parameters } & \\
\text { Groups }\end{array}$}} & Control group & Steroid group & \multirow{2}{*}{ P-value } \\
\hline & & No.20 & No.20 & \\
\hline \multirow{2}{*}{ 1st w BG } & Mean \pm SD & $146.45 \pm 15.02$ & $153.10 \pm 18.97$ & \multirow{2}{*}{0.227} \\
\hline & Range & $115-168$ & $115-180$ & \\
\hline \multirow{2}{*}{$2 \mathrm{nd} \mathrm{w}$} & Mean \pm SD & $157.95 \pm 16.34$ & $164.00 \pm 17.84$ & \multirow{2}{*}{0.270} \\
\hline & Range & $140-186$ & $129-188$ & \\
\hline \multirow{2}{*}{$3 \mathrm{rd} \mathrm{w}$} & Mean \pm SD & $152.70 \pm 14.94$ & $158.10 \pm 16.08$ & \multirow{2}{*}{0.278} \\
\hline & Range & $135-184$ & $125-185$ & \\
\hline \multirow{2}{*}{ 4th w } & Mean \pm SD & $151.10 \pm 10.24$ & $154.95 \pm 13.40$ & \multirow{2}{*}{0.314} \\
\hline & Range & $135-170$ & $135-179$ & \\
\hline \multirow{2}{*}{5 th $w$} & Mean \pm SD & $145.75 \pm 8.19$ & $151.60 \pm 13.58$ & \multirow{2}{*}{0.107} \\
\hline & Range & $132-164$ & $130-175$ & \\
\hline \multirow{2}{*}{ 6th w } & Mean \pm SD & $147.10 \pm 7.76$ & $152.50 \pm 12.65$ & \multirow{2}{*}{0.112} \\
\hline & Range & $135-162$ & $130-171$ & \\
\hline
\end{tabular}

Independent t-test Post prandial glucose (PPG)

There was statistically significant decrease in the incidence of receiving amitriptyline and carbamezapine in steroid group than control group with p-value < 0.001 and 0.037 respectively while there was no statistically significant difference found between the two studied groups regarding receiving paracetamol with $\mathrm{p}$ value $=0.091($ Table 5) .

Table (5): Comparison between control group and steroid group regarding treatment received

\begin{tabular}{|l|l|c|c|c|c|c|}
\hline \multicolumn{2}{|l|}{ Treatment Groups } & \multicolumn{2}{c|}{ Control group } & \multicolumn{2}{c|}{ Steroid group } & \multirow{2}{*}{ P- value } \\
\cline { 3 - 7 } & No.20 & $\mathbf{\%}$ & No.20 & \% & \\
\hline \multirow{2}{*}{ Amitriptyline } & No & 0 & $0.0 \%$ & 13 & $65.0 \%$ & \multirow{2}{*}{0.001} \\
\cline { 2 - 7 } & Yes & 20 & $100.0 \%$ & 7 & $35.0 \%$ & \\
\hline \multirow{2}{*}{ Carbamezapine } & No & 1 & $5.0 \%$ & 6 & $30.0 \%$ & \multirow{2}{*}{0.042} \\
\cline { 2 - 6 } & Yes & 19 & $95.0 \%$ & 14 & $70.0 \%$ & \multirow{2}{*}{0.176} \\
\hline \multirow{2}{*}{ Paracetamole } & No & 11 & $55.0 \%$ & 16 & $80.0 \%$ & \\
\cline { 2 - 6 } & Yes & 9 & $45.0 \%$ & 4 & $20.0 \%$ & \\
\hline
\end{tabular}

*: Fisher exact test

There was statistically significant increase in the satisfaction score in steroid group than control group with p-value < 0.001 (Table 6).

Table (6): Comparison between control group and steroid group regarding patients satisfaction score

\begin{tabular}{|c|c|c|c|c|c|}
\hline \multirow{3}{*}{$\begin{array}{l}\text { Patients } \\
\text { satisfaction }\end{array}$} & \multicolumn{2}{|c|}{ Control group } & \multicolumn{2}{|c|}{ Steroid group } & \multirow{2}{*}{$P$ - value } \\
\hline & No.20 & $\%$ & No.20 & $\%$ & \\
\hline & 16 & $80.0 \%$ & 0 & $0.0 \%$ & \multirow{3}{*}{$<0.001$} \\
\hline \multirow{2}{*}{\begin{tabular}{|l} 
Un Satisfied \\
Satisfied \\
Very Satisfied \\
\end{tabular}} & 3 & $15.0 \%$ & 2 & $10.0 \%$ & \\
\hline & 1 & $5.0 \%$ & 18 & $90.0 \%$ & \\
\hline
\end{tabular}

*: Fisher exact test 


\section{DISCUSSION}

The present study was carried on forty patients categorized into two groups to determine the pain relief efficacy of three successive ultrasound guided tibial nerve block at the ankle with bupivacaine and betamethasone as a primary outcome in the management of chronic painful diabetic neuropathy of the foot resistant to medical management compared to ultrasound guided placebo tibial nerve block. There was no difference in all studied patients regarding LANSS score pre block, while there was decrease in LANSS score in steroid received patients than control at different times of injection and during all follow up visits. There is decrease in the incidence of receiving amitriptyline and carbamezapine in steroid received patients than control group, while there is no difference found in all studied patients regarding receiving paracetamol, also there is increase in the patient satisfaction score in steroid group than control group.

Current study was in concurrence with Eissa et al. (2007) in which patient with (PDN) receiving tibial nerve block at the ankle level with either bupivacaine and triamcinolone or placebo (sterile saline) and found short-term (7 days post block) difference of LANSS score for patients who received placebo block to those receiving treatment drugs. The mean decrease from the baseline score was greater in treated patients than placebo.

Jeng and Rosenblatt (2012) found that peripheral nerve blocks (PNBs) entail that injection of corticosteroids, local anesthetics, neurolytic agents and/or sclerosing agents into or near peripheral nerves resulting in the temporary interruption of conduction of impulses in peripheral nerves or nerve trunks (somatic and sympathetic nerves). Van Beek et al. (2018) reported the effect of spinal cord stimulation (SCS) in 48 patients with painful diabetic peripheral neuropathy (PDPN) on pain ratings, treatment success and long-term treatment failure, and complications during a 5-year follow-up. Implantation of the SCS octapolar lead was performed, successful stimulation was considered if the NRS score for pain intensity during the day or night for the last 4 days of the trial period was at least $50 \%$ lower compared with baseline or if the Patient's Global Impression of Change (PGIC) score was $>6$ ("much improved" or "very much, improved") for pain and sleep. Outcome measures were assessed at baseline, after 12 months, and each year thereafter until 5years' follow-up. They reported that Spinal cord stimulation (SCS) is successful in reducing chronic pain symptoms in the lower extremities of patients with painful diabetic peripheral neuropathy (PDPN) up to 5 years after initiation of treatment. Complications and adverse events of SCS in PDPN were documented. Complications were defined as any event that required a patient visit (i.e., superficial or deep infections, pocket pain, painful or inadequate stimulation, battery or lead replacements or relocations, SCS reprogramming). Also this study had high failure rate and long duration till improvement.

Our study was more applicable, easier, higher efficacy and less complicated than this study, in this study Garrow et al. (2014) used acupuncture in PDN to assess pain in the real acupuncture relative to sham acupuncture, the intervention consisted of a total of 10 weekly sessions 
during which diabetes and blood pressure management continued as normal. Assessments of neuropathic pain were carried out using the Leeds Assessment of Neuropathic Symptoms and Signs (LANSS) Pain Scale The maximum score on the LANSS scale is 24 , with scores $>12$ indicating that neuropathic mechanisms are likely to be contributing to patients' pain. Lower limb pain intensity was measured on Visual Analogue Scale (VAS), and the Measure Yourself Medical Outcome Profile (MYMOP) was used to measure changes in health over time Patients in the active acupuncture group showed $16 \%$ improvement in LANSS score after acupuncture. In contrast, those in the sham group show $7.2 \%$ deterioration in LANSS symptoms. Six of $24(25 \%)$ patients in the active acupuncture group showed at least a $25 \%$ improvement compared with four of 21 $(19 \%)$ in the sham group. The LANSS score improved by an average of 2.1 points more in the treatment group than the sham group which would be considered as a moderate treatment effect. They found improvement in (LANSS score) in controlled acupuncture than placebo acupuncture more than base line.

Cheng et al. (2012) found that there is also evidence that the sympathetic nervous system may play an important role in painful diabetic neuropathy. Neither circulating nor epinephrine is higher in painful than painless diabetic neuropathy, and its concentration is correlated with the severity of neuropathic pain. Thus, painful diabetic neuropathy is suggested to be associated with a relatively higher number of functioning sympathetic fibers that may contribute to pain. Damaged peripheral nerves became hyper excitable through abnormal electrical connections that may have resulted in cross talking between sensory and sympathetic nerve fibers. Furthermore, patients with PDN had impaired sympathetically mediated vasoconstriction, contributing to inappropriate local blood flow regulation in these patients. Based on these observations, they hypothesized that sympathetic nerve blocks may reduce pain associated with diabetic neuropathy by reducing sympathetic outflow and improving circulation. They tested this hypothesis in a patient with severe PDN refractory to multiple pain medications by treating him with bilateral lumbar sympathetic block at the level of L3 under fluoroscopic guidance and injected a mixture of $12 \mathrm{~mL}$ of $1 \%$ Lidocaine and 20mgTriamcinolone on each side. The temperature, monitored in the plantar surface of the big toes, increased significantly, and NRS pain scores decreased substantially after the procedure (initial block). At his 2-month follow up, the patient reported "excellent "relief of his foot pain bilaterally for over 6 weeks, a decision was made to proceed with a repeat lumbar sympathetic block to further enhance the pain relief. Subsequent temperature and pain score changes were again noted at a follow up visit 4 weeks later, the patient again reported "significant, sustained" relief of his bilateral foot pain. He felt "dramatic" improvement of the "coldness and tingling pain" with the first injection with sustained relief that was further enhanced with the second procedure. By this point, his bilateral foot pain was 5 on the NRS three months following his second lumbar sympathetic block; therefore, a third 
bilateral lumbar sympathetic block was performed, Pain medications remained the same, and the patient was followed up in three months. Over the next two years, the patient continued to have lower extremity neuropathic pain as described above with good, sustained pain relief after each of subsequent lumbar sympathetic blocks.

There is no difference found among all studied patients regarding fasting blood glucose (FBG) as serum level is within the range $(90-125 \mathrm{mg} / \mathrm{dl})$ just before the scheduled injections. Also fasting serum glucose was close to $95 \mathrm{mg} / \mathrm{dl}$ in the majority of patients who received bupivacaine and corticosteroid.

This is similar to a study done by Eissa et al. (2007) as they found that Fasting serum glucose level was within the range (93-126 mg/dl) just before the scheduled injections. However, fasting serum glucose was close to $93 \mathrm{mg} / \mathrm{dl}$ in the majority of patients who received bupivacaine and triamcinolone.

\section{LIMITATION}

This study has some limitation such as adding comparative drugs which act on peripheral nerves dexmedetomidine, lidocaine, also increase the number of patients and duration of observation in this study.

\section{CONCLUSION}

Three successive ultrasound guided tibial nerve block at ankle level with $1 \mathrm{mg}$ betamethasone in $0.25 \%$ bupivacaine decrease LANSS score and analgesic requirements with more patient satisfaction in distal painful diabetic neuropathy resistant to medical treatment.

\section{REFERENCES}

1. Abbott C, Malik R, Van Ross E, Kulkarni J and Boulton A (2011): Prevalence and characteristics of painful diabetic neuropathy in a large community-based diabetic population in the U.K. Diabetes Care, 34: 2220-2224.

2. Balakrishnan $K$, Ebenezer $\mathbf{V}$, Dakir A, Kumar S and Prakash D (2015): Bupivacaine versus lignocaine as the choice of locall anesthetic agent for impacted third molar surgery a review. Journal of Pharmacy \& Pioallied Sciences, 7(1): S230.

3. Bennett MI, Smith BH, Torrance $\mathbf{N}$ and Potter J (2011): The S-LANSS score for identifying pain of predominantly neuropathic origin: validation for use in clinical and postal research. The Journal of Pain 6(3):149-58.

4. Callaghan B, Cheng H, Stables C, Smith A and Feldman E (2012): Diabetic neuropathy: clinical manifestations and current treatments. Lancet Neurol. 11: 521534.

5. Cashman CR and Höke A (2015): Mechanisms of distal axonal degeneration in peripheral neuropathies. Neuroscience Letters, 596:33-50.

6. Cheng J, Daftari A and Zhou L (2012): Sympathetic blocks provided sustained pain relief in a patient with refractory painful diabetic neuropathy. Case reports in anesthesiology, 1-5.

7. Daftary AR and Karnik AS (2015): Perspectives in ultrasound-guided musculoskeletal interventions. Indian $\mathbf{J}$ Radiol Imaging, 25:246-60.

8. Eissa AE, Elhosainy AM and Alansary MS (2007): Tibial nerve block in treatment of painfuldistal diabetic neuropathy. The Pain Clinic, 19(5):219-22

9. Gonano C, Kettner SC, Ernstbrunner M, Schebesta K, Chiari A and Marhofer $P$ (2012): Comparison of economic aspects of interscalene brachial plexus blockade and general anaesthesia for arthroscopic shoulder 


\section{HOSNY ABO ZIED FARG et al.,}

surgery. British Journal of Anaesthesia, 103(3):428-33.

10. Javed S, Petropoulos IN, Alam U and Malik RA (2015): Treatment of painful diabetic neuropathy. Therapeutic advances in chronic disease, 6(1): 15-28.

11. Jeng CL and Rosenblatt MA (2012): Overview of peripheral nerve blocks. Last reviewed November. UpToDate Inc. Waltham, MA,2.

12. Spallone V (2012): Management of painful diabetic neuropathy: guideline guidance or jungle? Curr Diab Rep. 12: 403-413.
13. Spallone V, Lacerenza M, Rossi A, Sicuteri $R$ and Marchettini $P$ (2012): Painful diabetic polyneuropathy: approach to diagnosis and management. The Clinical Journal of Pain, 28(8):726-43.

14. Van Beek $M$, Geurts JW, Slangen $R$, Schaper NC, Faber CG, Joosten EA, Dirksen CD, van Dongen RT, van Kuijk SM and van Kleef $M$ (2018): Severity of neuropathy is associated with long-term spinal cord stimulation outcome in painful diabetic peripheral neuropathy: five-year follow-up of a prospective two-center clinical trial. Diabetes Care, 41(1):32-8. 


\section{معالجه ألم اعتلال الاعصاب نتيجة مرض السكري بحصار

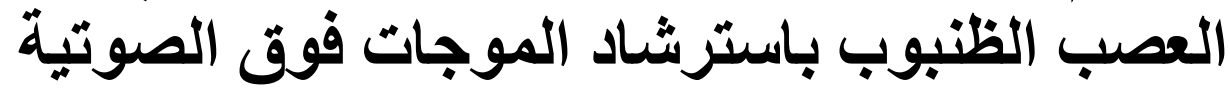

حنى ابوزيد فرج*، على عبدالله عيسى***، وفاء جابر أحمد* هُ

*قسم التخدير والرعاية المركزة، كلية الطب (بنات)، جامعة الأزهر

**قشم التخدير والرعاية المركزة، كلية الطب، جامعة الأزهر

خلقيـة البحــث: ان الاعــتلال العصــبى الطرفـى عبــارة عــن تليــف فـى الاليــاف العصــبية

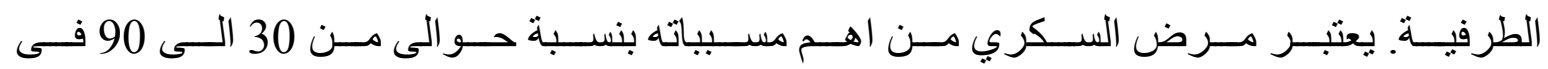

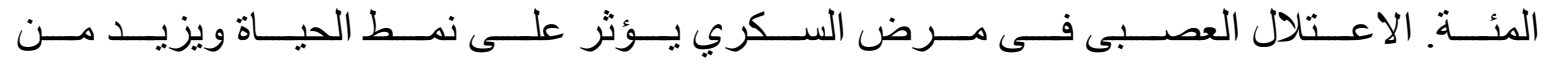

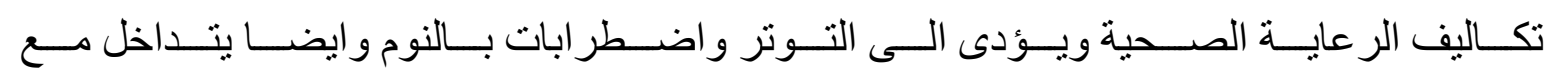

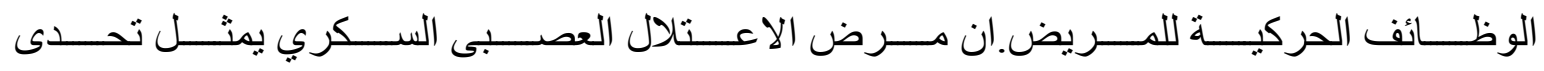

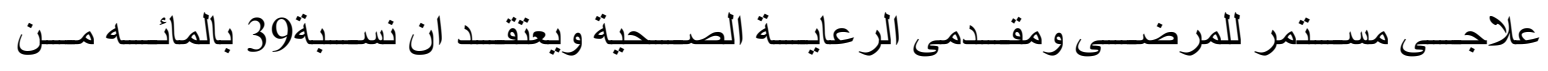
حالاته غير مستجيبة للعلاج.

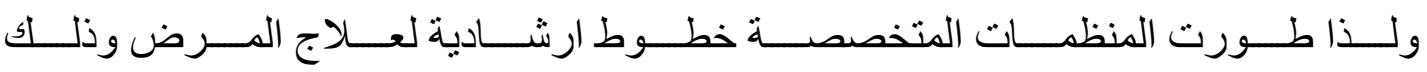

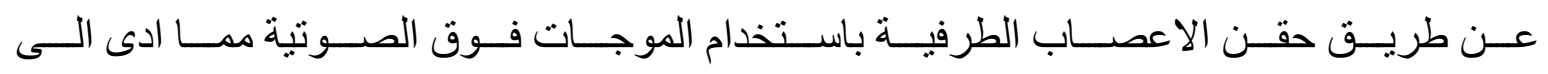

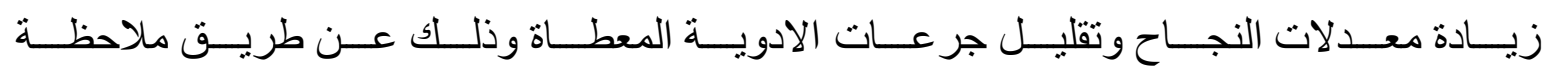

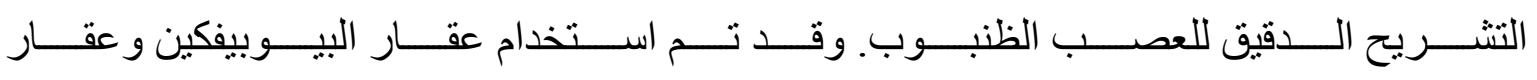
البيتاميثازون في الحقن باسترشاد الموجات فوق الصوتيه لحقن المرضي.

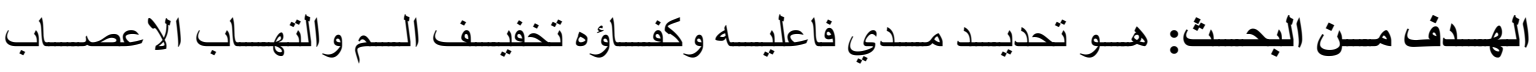

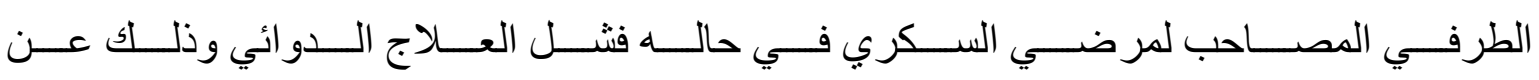

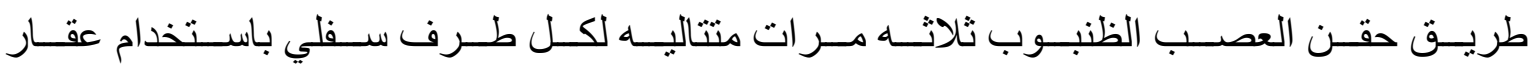

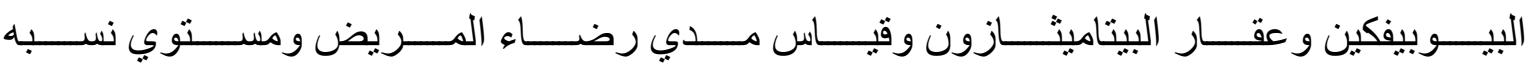
السكر بالدم.

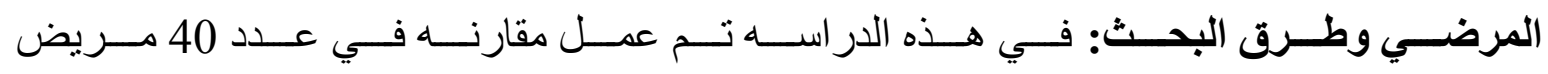

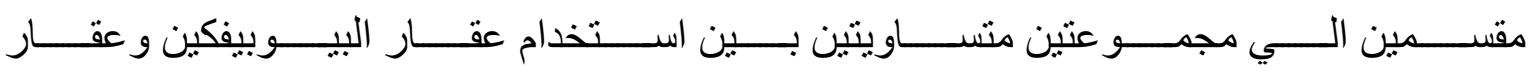

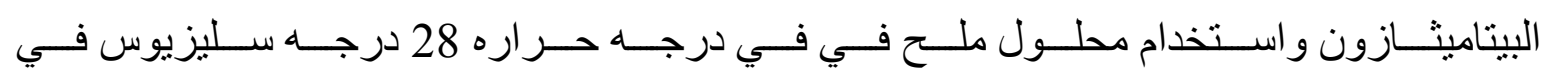




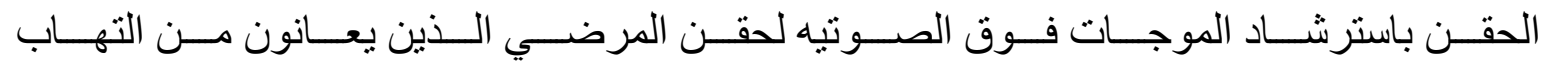
الاعصاب المصاحب لمرضي السكري.

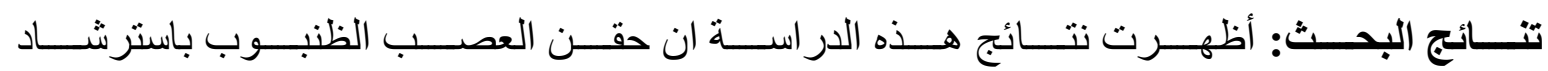

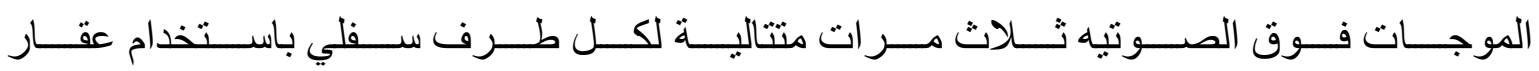

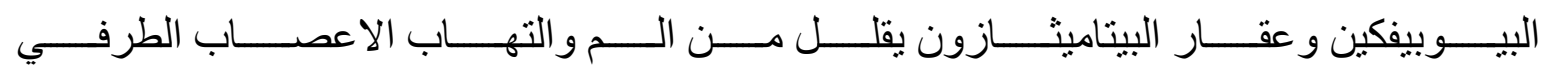

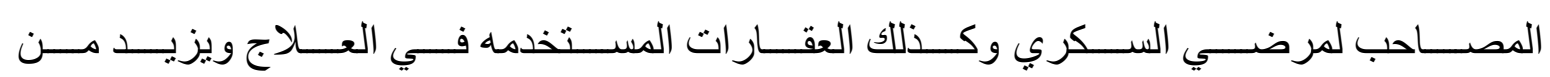
رضاء ور غبه المرضي.

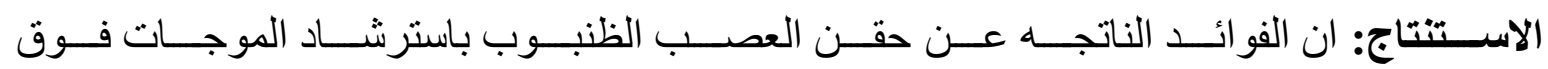

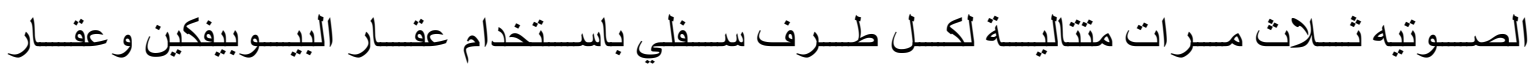

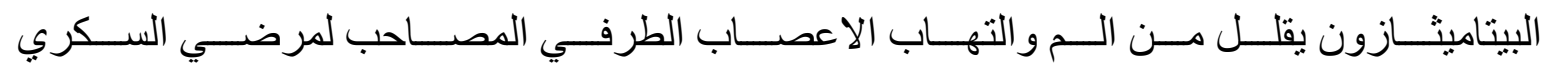
بعد التنخل الاول ويؤدي الي زو اله بعد التدخل الثالث. 